\title{
Isolated palatal palsy: a clinical rarity
}

\author{
Harpreet Singh, Rekha Mathur, Parminder Kaur \\ Department of Medicine, Post Graduate Institute of Medical Sciences, Rohtak 124001, Haryana, India.
}

\section{A B S T R A C T}

Acquired isolated palatal palsy is a rare disease. It is commonly seen in children. It usually presents with acute onset nasal regurgitation of fluids, rhinolalia, and palatal asymmetry. Many causes of this disease, such as infections, trauma, tumor, and brainstem lesions, etc., have been reported. However, the most plausible explanation is immunological/ischemic damage to the affected nerve. After ruling out major potential causes of this disease, the damage is often considered to be idiopathic in nature. This disease has a benign self-limiting course with excellent recovery. In accordance with a hypothesized immunological basis for this condition, treatment with steroids results in significant improvement in its clinical features.

Key words: Idiopathic, palatal palsy, rhinolalia

\section{INTRODUCTION}

Unilateral acquired isolated palatal (velopalatopharyngeal) paralysis is a clinical rarity usually seen in children. This isolated palatal palsy is the result of isolated involvement of the pharyngeal branch of the vagus nerve, which supplies motor fibers to muscles of the pharynx and soft palate. It was first described in 1976 by Edin et al. ${ }^{[1]}$ however its precise etiopathogenesis is still unclear. In the literature, infection-associated cranial mononeuropathy is frequently postulated as a possible cause, although a definite link is still uncertain. A case report of acquired isolated palatal palsy in a young adult is presented below, along with an overview of the available literature.

\section{CASE REPORT}

We report a case of a 15-year-old, completely immunized, previously healthy male, admitted with complaints of rhinolalia and nasal regurgitation of fluid for 2 days, which was sudden in onset, nonprogressive, and painless. The oral cavity showed no pseudomembrane. The gag reflex was present bilaterally, but there was less movement of the palate on the right side, and the uvula was deviated toward the left side upon

\begin{tabular}{|l|l|}
\hline \multicolumn{2}{|c|}{ Access this article online } \\
\hline Quick Response Code: & \\
\hline & Website: \\
\hline & www.nnjournal.net \\
\cline { 2 - 2 } & DOI: \\
\hline
\end{tabular}

phonation [Figure 1]. The vocal cords were normal on both sides. All other vital parameters and examinations were normal.

Laboratory tests showed a hemoglobin concentration of $15.2 \mathrm{~g} / \mathrm{dL}$, leukocyte count of $7000 / \mathrm{mm}^{3}$, differential leukocyte count of $58 / 38 / 2 / 2$, and absolute platelet count of $2.5 / \mathrm{mm}^{3}$. Blood and throat swab cultures were sterile. Cerebrospinal fluid analysis showed a leukocyte count of $4 / \mathrm{mm}^{3}$ consisting entirely of lymphocytes, sugar levels of $54 \mathrm{mg} / \mathrm{dL}$, and protein levels of $29 \mathrm{mg} / \mathrm{dL}$. Viral serology for human immunodeficiency virus, hepatitis B virus (HBV), herpes simplex virus (HSV), and Japanese encephalitis virus was negative. Due to resource constraints, however, other viral causes could not be ruled out. Chest X-ray, electrocardiogram, and diffusion-weighted magnetic resonance imaging (MRI) of the brain revealed no abnormalities [Figure 2].

A short course of prednisolone at $0.5 \mathrm{mg} / \mathrm{kg} /$ day was prescribed for 5 days, followed by $0.25 \mathrm{mg} / \mathrm{kg} /$ day for another 5 days. On the 7th day after admission, rhinolalia and nasal regurgitation of liquids subsided and the uvula was central upon phonation [Figure 3]. The patient was re-evaluated every 2 weeks for the next 2 months. He remained asymptomatic during follow-up visits.

\section{DISCUSSION}

Isolated acquired velopalatopharyngeal hemiparalysis is rare, affecting primarily males (80\%) in their first or second decade of life. ${ }^{[2]}$ Generally, it presents with rhinolalia and ipsilateral nasal escape of fluid with

Corresponding Author: Dr. Rekha Mathur, Department of Medicine, Post Graduate Institute of Medical Sciences, Medical Road, Rohtak 124001, Haryana, India. E-mail: drrekhamathur04@gmail.com 


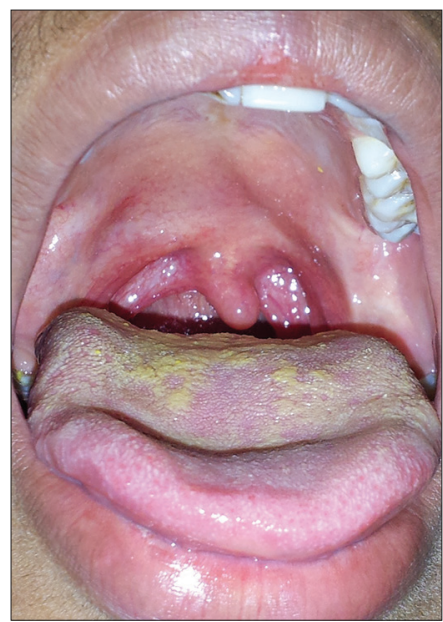

Figure 1: Uvula is deviated to the left side on admission

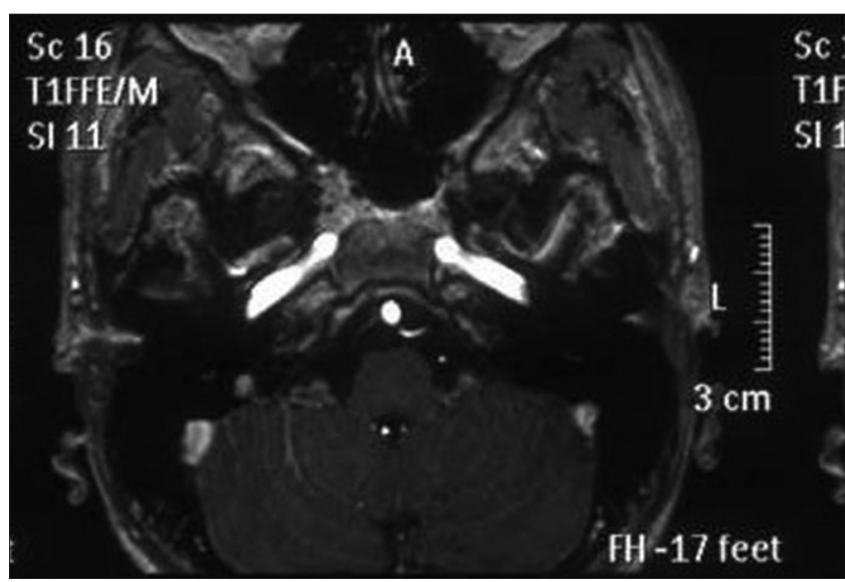

Figure 2: Magnetic resonance imaging of the brain showing no abnormalities

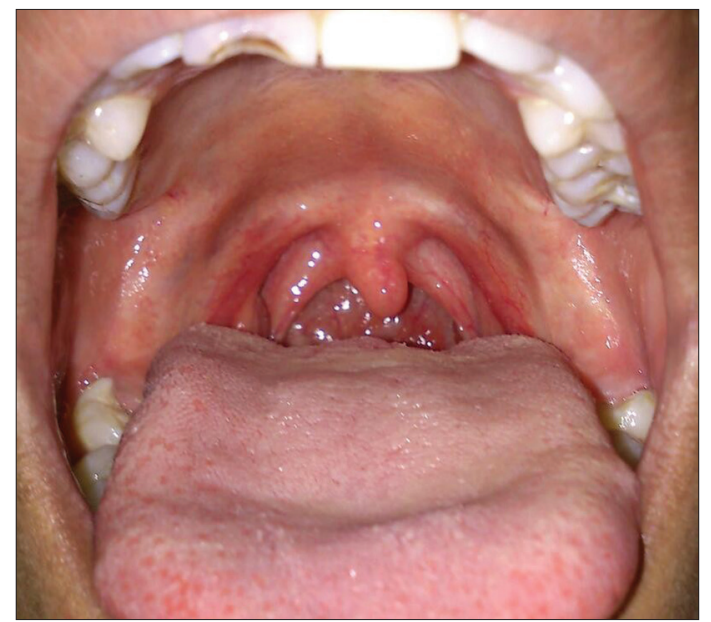

Figure 3: Uvula is central and palatal archs are bilaterally symmetrical on the 7th day after admission

varying degrees of dysphagia, and commonly mimics brainstem lesions.

The etiopathogenesis of this condition is still elusive. Two probable mechanisms have been hypothesized to explain its etiopathogenesis: infectious (mainly viral) and vascular. ${ }^{[3]}$ The possibility of an infectious/ postinfectious origin has been well-documented. ${ }^{[4,5]}$ For example, acquired isolated palatopharyngeal palsy is a well-documented postdiphtheritic complication. ${ }^{[4]}$ The increased prevalence of respiratory and gastrointestinal tract infection and the presence of relatively immature neural tissue in children may lead to more damaging neuroimmune responses to infection, explaining the increased vulnerability during childhood. The vascular hypothesis proposes that ischemia of roots of the glossopharyngeal and vagus nerves due to undetermined causes leads to lower motor neuropathy manifesting as palatopharyngeal incompetence. ${ }^{[6]}$

Although isolated palatal palsy is often an idiopathic disease, establishing this idiopathic nature requires the exclusion of other possible factors such as trauma (adenoidectomy or craniofacial trauma), infection (diphtheria, enteric infection, or poliomyelitis), neuromuscular disorders (Guillain-Barré syndrome or motor neuron disease), cranial vessels (internal carotid artery aneurysm or vascular insult), and others (syringobulbia, inflammatory disease affecting various brain stem nuclei and tracts, or tumors, especially of the posterior fossa, which usually have a benign course). ${ }^{[5,7]}$ Definitive viral etiologies for HSV, Coxsackie, Rubeola, HAV, Varicella, and Epstein-Barr virus have also been established. ${ }^{[4,5,7]}$ Isolated mononeuropathy generally follows infections of the respiratory tract like infectious mononucleosis and parvovirus B-19. ${ }^{[8,9]}$ Cerebral MRI must also be performed as it allows the exclusion of expansile, ischemic, or demyelinating lesions of the brainstem. Thus, to establish the idiopathic nature of this illness requires exhaustive investigation. Understanding the somatotropic organization of the vagus nerve and associated brain nuclei may help to explain the isolated palatopharyngeal involvement of this condition. In some rare cases, involvement of the cephalad portion of the vagus nerve results in isolated palatopharyngeal palsy. ${ }^{[5]}$ Laryngoscopy provides direct evidence for sparing of the vocal cords in this condition as concurrent vocal cord palsy has been excluded in cases of isolated acquired velopalatopharyngeal palsy (as in the present case).$^{[5]}$

In a systematic review of the literature from 1960 to 2012 , only 36 case reports of acquired isolated palatal palsy were found. ${ }^{[10]}$ The cause of this condition remains undetermined. The disease usually runs a self-limiting course with complete recovery within 2-3 weeks in more than $85 \%$ of cases. ${ }^{[1,2]}$ Prognosis is excellent. Although oral glycerol and steroids have been used empirically for early recovery, no specific treatment is required. ${ }^{[11]}$ Follow-up is mandatory to observe the further course of the disease. Still, establishing the benign nature of this disorder requires exhaustive investigation in order to differentiate it from other disorders. 


\section{REFERENCES}

1. Edin M, Sveger T, Tegner H, Tjernström O. Isolated temporary pharyngeal paralysis in childhood. Lancet 1976;1:1047-9.

2. Villarejo-Galende A, Camacho-Salas A, Penas-Prado M, García-Ramos R, Mendoza MC, Simón de las Heras R, Mateos-Beato F. Unilateral isolated paralysis of the soft palate: a case report and a review of the literature. Rev Neurol 2003;36:337-9.

3. Alp H, Tan H, Altunkaynak S, Orbak Z. Idiopathic unilateral paralysis of the palate in childhood. Pediatr Neurol 2005;33:134-5.

4. Havaldar PV. Diphtheria in the eighties: experience in a south Indian district hospital. J Indian Med Assoc 1992;90:155-6.

5. Prasad PL, Prasad AN, Patnaik SK. Unilateral palatal palsy with viral hepatitis. Indian J Pediatr 2007;74:1039-40.

6. Lapresle J, Lasjaunias P, Thévenier D. Transitory paralysis of cranial nerves IX, X and XII as well as the left VII after angiography. Contribution to the ischemic pathology of the cranial nerves. Rev Neurol (Paris) 1980;136:787-91.
7. Sondhi V, Patnaik SK. Isolated idiopathic unilateral paralysis of soft palate and pharynx. Indian Pediatr 2011;48:237-9.

8. Krotochwil-Skrzypkowa M, Stokowski L. Paresis of the palate in the course of infectious mononucleosis in a 7-year-old girl. Pediatr Pol 1968;43:871-4.

9. Soares-Fernandes JP, Maré R. Isolated velopalatine paralysis associated with parvovirus B19 infection. Arq Neuropsiquiatr 2006;64:603-5.

10. Walter V, Nisa L, Leuchter I. Acute isolated velopharyngeal insufficiency in children: case report and systematic review of the literature. Eur Arch Otorhinolaryngol 2013;270:1975-80.

11. Auvin S, Cuvellier JC, Vallée L. Isolated recurrent palatal palsy in a child. Neuropediatrics 2003;34:278-9.

Cite this article as: Singh $\mathrm{H}$, Mathur R, Kaur P. Isolated palatal palsy: a clinical rarity. Neuroimmunol Neuroinflammation 2015;2(3):190-2.

Source of Support: Nil. Conflict of Interest: No.

Received: 16-10-2014; Accepted: 13-01-2015 